\title{
Assessment of Toxicity and Safety Profiles of Nanoparticles
}

\author{
Kundan Kumar $^{1}$, Ravi Kant Singh ${ }^{1}{ }^{\mathbb{D}}$, Pankaj Kumar Tyagi ${ }^{2, * \mathbb{D}}$, Dilip Gore ${ }^{3}$ \\ Amity Institute of Biotechnology, Amity University Chhattisgarh, Raipur, C.G.-493225, India \\ Department of Biotechnology, Noida Institute of Engineering \& Technology, Gr. Noida, U.P.-201310, India \\ Saibiosystems Pvt. Ltd., Nagpur, Maharashtra, India \\ Correspondence: pktgenetics@gmail.com;
}

Scopus Author ID 34881106500

Received: 27.07.2020; Revised: 25.09.2020; Accepted: 28.09.2020; Published: 3.10.2020

\begin{abstract}
The world of medicine explored the use of nanoparticles in therapeutics in the last two decades. Owing to the advantages nanoparticles offer, they are proving beneficial to overcome many drawbacks faced by small drug molecules. Since the nature, architecture, shape, size, and mechanism of action of nanomedicines totally different from regularly used drugs, it is important to work on the possible toxicity these nanoparticles are causing so that its safety can be ensured. In today's scenario, a lot of industries and institutes are synthesizing nano drugs, so it is important to check its toxicity and safety evaluation under in vivo and in vitro conditions, as it has come to fore that number of metal and carbon-based nanoparticles, although proving useful further display increased toxicity. Taken into consideration nanoparticle toxicity and safety, the present review discusses the exact working of nanoparticles at the molecular, cellular, and physiological levels and the toxicity associated with it. The present strategies for safety assessment have also been reviewed. The research involving nanomaterials in therapeutics demand strict regulation in nanoparticle synthesis, its usage, properly regulated clinical trials ensuring safety assessment.
\end{abstract}

Keywords: nanoparticles synthesis; nano drugs; safety regulation; nanotoxicity.

(c) 2020 by the authors. This article is an open-access article distributed under the terms and conditions of the Creative Commons Attribution (CC BY) license (https://creativecommons.org/licenses/by/4.0/).

\section{Introduction}

The term "Nanomedicine" denotes the use of nanoparticles for therapeutic and diagnostic applications. The nanoparticles are mainly synthesized by using a number of metal precursors, biomolecules, and polymers such as proteins [1], polymers [2], metals [3, 4], lipids $[5,6]$, and carbon. The use of nano-based drugs has been demonstrated to cure a number of diseases such as diabetes, cancer, infectious diseases, and allergy [7, 8]. In success story, now the number of nanoparticles set in clinical trials and approved for its use [9, 10]. In countries like the USA, China, more than 12 Liposomal drugs are clinically approved, while several are taken into clinical trials for evaluation $[11,12]$.

The features of nanoparticles as a drug explored further since nanoparticles able to showcase electrical and optical properties, which has promising importance in therapies. In a success story, Researchers have successfully used nanoparticle in combination with external energy. It thermally ablates the targeted tissues. The reports published were gold nanoparticles used to be useful with infrared light [13] as well as with radio waves [14], and another report, the use of iron oxide nanoparticles with a magnetic field, able to generate heat has been demonstrated [15]. 
Nanoparticles also protect themselves from early degradation and ensure sustained and controlled drug release. The advantage of nanoparticles lies with their ability to accumulate drug in the targeted tissue, which justifies its use for better actions. The action of any drug has to face a number of body barriers so that drugs can function at the desired location [16]. The main barriers in drug deliveries are enzymatic and mechanical degradation, renal clearance, vascular endothelium, extracellular matrix, cell membrane, the lysosomes, and membrane pumps. These barriers are promisingly handled by the nanoparticles and reported profoundly efficient by in vivo studies [17].

By considering all these advantages, the use of nanoparticles in disease treatment certainly finds a better place. The increasing research on nanoparticles, especially in nanomedicines, now demands its safety assessment so that its potential toxicity for nanotherapeutic could be put forward. The nanoparticles are unique in its shape, size, and make, and hence those cannot be tested with conventional methodologies generally used for checking bulk molecules; hence, it is imperative to develop stricter guidelines for the approval of nanoparticles once we considered with other molecules. The current paper reviews the key work on nanoparticles toxicity, its effect with systemic response and safety assessment.

\section{Assessment of nanoparticles for toxicity/nanotoxicity}

The use of nanoparticles in the medical field has reported showcasing great promise, but the toxicity associated with many nanoparticles, as reported by many studies, has restricted its usage and a strict vigilance is the need of the hour to prove its safety. In a study, the use of iron oxide nanoparticles registered harmful effects under in vitro and in vivo conditions, and this negative effect is related to its ability to produce reactive oxygen species $[18,19]$. In one study, silver nanoparticles are also registered with cytotoxic effects [20, 21]. It is further challenging with nanoparticles as its toxicity has been linked with its size. For example, gold nanoparticles having a diameter of $1.4 \mathrm{~nm}$ registered its toxicity, whereas the same nanoparticles having $15 \mathrm{~nm}$ size did not display any toxicity $[22,23]$. The study also showcased that NPs are becoming toxic to the tissue under different shapes and morphology as recorded with carbon nanotubes [24].

However, nanoparticle cytotoxicity and hazardous effect have been well addressed to use it in targeted cell killing of diseased tissue, specifically in the case of tumors and cancers. Provided nanoparticles must be featured with selective targeting so that such a drug could be put forward. The modification of NPs, especially its surface, also reported promising to reduce its toxicity yet to make them effective [25]. In one such report, the involvement of the hydroxyl group to gadolinium fullerene nanoparticles able to reduce its toxicity since it has prevented ROS generation [26, 27]. The success stories also reported when iron oxide nanoparticles coated with a polymer which has improved cell viability by reducing NPs toxicity [28].

\subsection{Combating drug toxicity using nanocarriers.}

The research is going on that how drug targeting to specific tissue can be improved and reduces its toxicity at the same time. Nanotherapeutics associated nanoparticles with drugs as a preferred choice. The success of nanotherapeutics underlined by reduced toxicity than their free-drug counterparts. The first drugs were approved as nanomedicine marketed as Doxil by the USFDA. The drug is having the origin of the liposomal formulation of doxorubicin. The drug is preferred over it free-doxorubicin since it is useful in reducing cardiotoxicity [29]. The 
major research reports are indicating with associated with nanoparticles and drug delivery when the drug side effects were lowered down its indicate the improvement in the accumulation of the drug in the targeted tissue, which is again ensuring the reduction in toxicity and doses with better therapeutic efficacy. As demonstrated earlier, that once injected drug accumulates as only $0.01 \%$ in targeted tissues [30]; in contrast, the use of a drug with NPs improves its bioavailability to $1-5 \%$, making it a big success [31].

The success of NPs also been guessed since those cannot freely pass through the vasculature of any tissue easily, while small molecules can; this feature is utilized for increased deposition of nanoparticles in tumor tissue to enhanced permeability and retention (EPR) effect. The EPR effect does exist between the vasculature of tumors and normal tissues [32, 33].

The toxicity of the drug further reported being reduced in the presence of nanoparticles once they were used as an alternative for a stabilizing drug agent. The NPs are more effective once drugs are of class belongs to hydrophobic therapeutics [34-36]. Since in medicine, the number of drugs belongs to water-insoluble categories and to make them dissolved, a number of harmful solvents are used. These solvents are toxic in nature, as confirmed by in vivo and in vitro testing. In one such example, the use of dimethyl sulfoxide for drug testing with cell culture is common [37]. However, DMSO turned out to be toxic to the tissues and cells under in vitro and in vivo studies [38-41]. In a similar manner, the number of hydrophobic drugs is dissolved in toxic solvents such as polyethoxylated castor oil, dehydrated ethanol mixture [42], and polysorbate 80 [43], and many others. These hydrophobic drugs in the future could be replaced with NPs so that rising toxicity could be controlled.

\subsection{Toxicity of different nanoparticles.}

The dendrimers are highly branched, monodisperse, 3D macromolecule characterized organic nanoparticles used as nano-drug delivery vehicles to carry specific sizes and shaped drug molecules. The dendrimers exhibit hydrophilic periphery and hydrophobic core and are found to be useful in drug loading features [44]. Its real use evidence as a dendritic polymer that able to improve the doxorubicin delivery along with many cytotoxic drugs to solid tumors. The application of dendrimers as a carrier is to reduce the drug load towards noncancerous cells/tissues, and the toxicity of dendrimers against hemolytic cells was reported and found to be toxic $[45,46]$. The toxicity of these nanoparticles was reported low with anionic dendrimers and with modified dendrimers since they can mask peripheral cationic groups. These NPs able to minimize hemolytic activity. This gives us a direction that surface engineering or dendrimers will improve its utility by reducing its toxicity, making them safe for use, especially in the biomedical field.

The application of nano drugs has improved and made it to the market as a drug carrier also. Recently, the toxicity concern about these nanosized particles grown to a high level. The particles proving to be a major toxicological concern were noted below 100nm [47, 48]. These small size nanoparticles $(<100 \mathrm{~nm})$ can easily get internalized by any cell via pinocytosis, which is a real concern. Instead, nanoparticles $>200 \mathrm{~nm}$ only gets internalized by macrophages, causing limited cell toxicity. This phenomenon indicated that small nanoparticles could access any cell of the body, by which increased toxicity potential of them cannot be ruled out. The exposure of nanoparticles via the oral route is reported to be more severe since they showcase higher $\mathrm{C}_{\max }$ and short $\mathrm{T}_{\max }$, along with higher and more rapid systemic exposure of drugs, which gives many severe side effects [49]. 
The better efficiency of biopharmaceutical drugs and/or its therapeutic index use of lipid nanosystems, mainly in the form of liposomes and solid lipid nanoparticles, is recommended [50]. These types of lipid nanosystems offer many advantages since they are well tolerated by living systems since they are produced from common physiological compounds. This ensures that metabolism should decrease the risk of acute and chronic toxicity [51].

The development of self-emulsifying drug delivery systems providing a new way of drug delivery system, ensuring great safety once we are interested in lipophilic drugs [52-54]. The SEDDSs are further classified as self-micro emulsification drug delivery systems. (SMEDDSs) or self nano-emulsification drug delivery system (SNEDDS), which are purely based on the size range of their droplets [55]. Here SMEDDSs ranging between droplet size of 100 to $250 \mathrm{~nm}$ and with finer nano-emulsions, of diameter less than $100 \mathrm{~nm}$ named SNEDDS. The success of SEDDS evidenced with a product as a dry emulsion of cyclosporine A useful for Asthma treatment, allograft rejection, and for chronic obstructive pulmonary disease making it a future drug delivery prospect [56]. Liposomes are able for encapsulation and deliver both hydrophilic and hydrophobic substances afflictively after conjugations with polymers. These combinations assure attenuating the opsonization of the liposomes and rapid clearance. The use of PEG-modified liposome is on the rise with the advantage of a significant reduction in non-specific RES uptake [57].

\section{Safety assessment of nanoparticles}

The efficient use of NPs in nanomedicines could only be ensured its safety assessment is assured at different concentrations, shape, size, and mechanism of action. However, when we are looking at the methodologies available with us to date, these tests or protocols are specially made for the large or small molecules, but those do not ensure it will work equivalent with nanoparticles. In today's scenario, we are testing promising drug candidates under in vitro and in vivo protocols, and then only the approved drug comes into the market. In a recent scenario, since we are synthesizing nanoparticles for therapeutics, its safety assessment is a prerequisite. However, NPs behaves differently than small molecules in terms of its shape, size, surface properties, and molecular dynamics. The incidences came to force that NPs can sediment, aggregate once interacts in a different solvent, and that changes in molecular dynamics. These properties make them a tough molecule to analyze under testing conditions, and many times does affect analyzing result in a better way. In one such report, where NPs are mutagenic under mammalian assay, but a similar incidence did not record with the Ames test where bacteria used as a screening biological host [58]. The suggested failure of the use of Ames looks at with NPs linked with their incapacity to penetrate the bacterial membrane [59]. But this report remains questionable since NPs are reported to pass on bacterial membranes once traced inside the bacterial cell, indicated that the failure of the Ames test depends on other factors. In confirmation of the study, NPs can interact with tetrazolium salt in the MTT (3-4,5-dimethyl thiazol-2-yl)-2,5-diphenyltetrazolium bromide has been reported, thereby interfering in accurate measurement cannot be ruled out [60]. This interaction of NPs with MTT chemicals found to be affecting its toxicity, and it is reported to reduce by $60 \%$.

In addition to the selection of proper methods for NPs assay, it is most important to gather information about its dosage of testing, as in many studies use of NPs in high concentrations has been reported with in vitro conditions. Since the same concentration is not achievable under in vivo conditions, hence giving false information about its toxicity been 
tested [61]. As it is estimated that under 2D culture testing, brain microglia cells reported to be damaged with $25 \mu \mathrm{g} / \mathrm{ml}$ of titanium dioxide [62], but if these NPs made available at high concentration still it will not damage even epithelial cells in the lung since those will not be exposed to this dose $[63,64]$.

The incidence of utilizing a high dosage of NPs and resultant its carcinogenicity is mainly recorded since that concentration cannot be applicable under in vivo conditions; for example: - carbon nanotubes prove carcinogenic once given intravenously at a concentration of $\sim 3 \mathrm{mg} / \mathrm{dose}$ (62), which is equivalent to the $10 \mathrm{~g} / \mathrm{human}$. That means even at this concentration, blood glucose levels are also reported being toxic [65]. Once inside the body, it is assured that NPs are acting uniformly at a given dose every cell type, but it is not so. In a real sense, a macrophage will recognize NPs and tries to engulf as much as it can, making it less available to other cell types. Hence, it concludes that it is tough to correlate the results of in vitro test with in vivo conditions. Further, once we are synthesizing nanoparticles, it remains with traces of impurity, which is not getting separated or when attempted to do so, making them a hazardous combination to use $[66,67]$.

\subsection{Safety features of nanoparticles.}

By taking a keen interest in nanoscience and by considering the huge potential in the field of nanotechnology, everyday new nano-compounds are getting synthesized in the academic and industrial sectors $[8,50,68]$. As come to force, 'nanoscience' deals with the manipulation of materials at atomic, molecular, and macromolecular scales. These nanostructures are built to assess its unique application at the nanometer scale [69-71]. In the hunt of better molecules- researchers are searching utility in nanoparticles, especially in fields such as electronics, medicine, food science, biotechnology, and pharmaceutics. The success stories are many with the development of nanofillers, nano diagnostic kit, and nano drugs also [50]. Looking at these prospects, now time must come that assess its safety measures, and new methodologies need to be searched out so that better assessment could be carried out. As it has confirmed that nanoparticles can bring many cellular changes such as oxidative stress, inhibition of cell division, cell death, and genetic damage, it is imperative to consider this before testing in any formulation. Further, NPs are variable in features with respect to its size, surface, and chemical composition, which always remain the concern [71-73] taken into the consideration of blooming features of nanotechnology now its safety assessment branch known as nanotoxicology, came to the fore to strengthen its fate in the field of applications.

Solid-lipid nanoparticles set as an alternative to the liposome formulations having many advantages such as a) systematic release of the drug, b) low-cost production, c) ease of mass production, and d) improved physical stability for use. In addition to advantage, several disadvantages are also reported, such as a) limited loading capability, b) relatively higher water content of the dispersion, c) drug expulsion after recrystallization [74]. These drawbacks are overcome by linking peptide, small molecules, proteins to the solid lipid nanoparticles so that it improves pharmacokinetic behavior [75-77]. The use of micellar nanoparticles, which is a spherical nanostructure, has improved its share in drug delivery research [78, 79]. These nanoparticles are mastered to trap hydrophobic drugs and then assure improved absorption and distribution of internal drugs by avoiding opsonization and phagocytic clearance by RES uptake [80]. The use of micellar nanoparticles registered many successes in drug delivery studies such as paclitaxel [81], anticancer drugs NK105 [82] but also suffered from few disadvantages such as rapid elevation of systemic exposure and toxicity of the surfactant. 
In the use of the recent advances of polymeric nanoparticles, having a size range between 10-1000 $\mathrm{nm}$ able to encapsulate drugs inside a polymeric matrix, which makes them potent to protect the drug from enzymatic and hydrophilic degradation [83]. The polymeric nanomaterial is able to release drugs to the target tissue by desorption, nanoparticles erosion, or via diffusion through the polymer matrix. The commercial uses of polymeric nanoparticles are now employing biodegradable carriers conjugates with proteins, DNA, and RNA-based drugs with less toxicity, and this type of finding may be open new possibilities for researchers in the field of toxicity [84]. The success of polymeric nanoparticles lies with the coating with nonionic surfactants, and resultant presence of surfactants marked by reduced immunological interactions, mainly opsonization. The reduction in interaction between drug chemical groups occurring via Vander Waals forces, hydrogen bonding, and hydrophobic interaction has been reported as a success of these nanoparticles $[85,86]$.

In the present research era, we are gathering huge information about nanoparticles since they are easy to synthesize yet tough or time-consuming to actually understand its environmental and safety factor, which we are ignoring for the most of the time in today's research where we are testing the efficiency of nanoparticles for diminishing toxicity of chemotherapy drugs or other drugs. On the other hand, some NPs themselves, proving to be cytotoxic, an allergic compound, or bring about inflammation [87]. Another major effect of NPs lies with their ability to produce reactive oxygen species (ROS) and free radicals. These effects are proving negative to bring about DNA damage, multi nucleus formation, inflammatory events, and fibrosis [88]. The nanoparticles are also proving toxic when those are accumulating within the cells; this situation arrives once those are given in a high dose or exposed for the long term. However, the upper size limit for it has not been ascertained but reported to be ranging between $65 \mathrm{~nm}$ and $800 \mathrm{~nm}$ [89]. It is further put forward that nanoparticle toxicity remains complex and multifactorial in the feature. The toxicity also remains dependent on the shape, size, and surface properties, mainly the charge, area, and reactivity; it is further confirmed that the size of NPs is most important for toxicity than its composition. The role of nanoparticles surface area also remains useful to predict its toxic and pathological response to particle mass dose [88]. As per shape and size investigation, NPs having needle-shaped carbon nanotubes, nanofibers, and nanowires proving more lethal that brings fibrotic lung disease and rare tumors [90]. The polycationic nanoparticles are also proving toxic to bring about necrosis and apoptosis, and hence while using them as nanocarriers, it is vital to consider their safety. The nanoparticles bring about surface reactivity by bringing about chemical damage to the surrounding tissues. As recorded micron-sized particles once get deposited in the central airways, it does chock lung periphery, causing greater inflammation in that part [91]. The application of nanoparticles is on the rise once they are utilized in cosmetics, stain-resistant clothing, sunscreens lotions. Taken into consideration, a number of researches put forward the minimal toxicity of NPs with skin, and it remains dependent on skin penetration and skin condition also. In some contrasting result, nanoparticles proving to be cytotoxic, and events of proinflammatory to dermal cell lines recorded under in vitro conditions $[87,92,93]$. This study demands the safety of nanoparticles under in vivo conditions to clarify the chronic dosage of nano drugs [87]. In success stories, systemic toxicity of nanoparticles confirmed by acute toxicity assay mainly via a 50\% lethal dose (LD50). In a common investigation, nanoparticles are generally taken up to the RES, and the number of target organs remains a member of RES, such as spleen and liver [94, 95]. In a different application, now the biomedical application of nanomedicine, the NPs get a coating of 
biocompatible materials that assist them in escaping from opsonization and avoid the RES uptake. This makes the shift away from nanoparticles from the RES. Hence it is important to understand how the potential of nano drugs as toxic compounds is available within in vivo system. The study should consider the factors like the route of administration, and this will surely assist in better understanding of risk factors associated with nano drugs and nanomaterials in the human body so that in the coming time, we can explore the potential of nano drugs in a better way.

\section{Conclusions}

Another human-made nano molecules are proving to be the savior of human life. These molecules are appearing very tons the equal to different standard tablets; however, the mechanism of action stays varied. This exchange in motion makes them unique, strong but challenging to look at considering they are nanosized, having recreation structured on charge, shape, measurement, and activation with different molecules. Since we additionally recorded that nanoparticles additionally work otherwise in mixture with biomolecules, it is as soon as once more will become precedence look at as soon as it goes into the machine of the host. As it comes to the fore that quantity of nano drugs like carbon and steel produced proving to be eliciting an immune response, amplify ROS generation, cytotoxic, and worried in cell compartment disruption. In the view, the current evaluation mentioned how researchers are discovering new methodologies, following scientific trials to display screen these new nano pills to discover the opportunity of toxicity and protection for future nanomedicine use.

\section{Funding}

This research received no external funding.

\section{Acknowledgments}

The authors are highly thankful to the Directors and Head of the Department for providing the necessary facility and continuous encouragement for research work.

\section{Conflicts of Interest}

The authors declare no conflict of interest.

\section{References}

1. Choi, K.M.; Choi, S.H.; Jeon, H.; Kim, I.S.; Ahn, H.J. Chimeric Capsid Protein as a Nanocarrier for SiRNA Delivery: Stability and Cellular Uptake of Encapsulated SiRNA. ACS Nano 2011, 5, 8690-8699, https://doi.org/10.1021/nn202597c.

2. Molinaro, R.; Wolfram, J.; Federico, C.; Cilurzo, F.; Di Marzio, L.; Ventura, C.A.; Carafa, M.; Celia, C.; Fresta, M. Polyethylenimine and Chitosan Carriers for the Delivery of RNA Interference Effectors. Expert Opin Drug Deliv 2013, 10, 1653-1668, https://doi.org/10.1517/17425247.2013.840286.

3. Shen, J.; Kim, H.-C.; Mu, C.; Gentile, E.; Mai, J.; Wolfram, J.; Ji, L.; Ferrari, M.; Mao, Z.; Shen, H. Multifunctional Gold Nanorods for SiRNA Gene Silencing and Photothermal Therapy. Adv Healthc Mater 2014, 3, 1629-1637, https://doi.org/10.1002/adhm.201400103.

4. Xu, L.; Liu, Y.; Chen, Z.; Li, W.; Liu, Y.; Wang, L.; Liu, Y.; Wu, X.; Ji, Y.; Zhao, Y.; Ma, L.; Shao, Y.; Chen, C. Surface-Engineered Gold Nanorods: Promising DNA Vaccine Adjuvant for HIV-1 Treatment. Nano Lett 2012, 12, 2003-2012, https://doi.org/10.1021/nl300027p.

5. Gentile, E.; Cilurzo, F.; Di Marzio, L.; Carafa, M.; Ventura, C.A.; Wolfram, J.; Paolino, D.; Celia, C. Liposomal Chemotherapeutics. Futur Oncol 2013, 9, 1849-1859, https://doi.org/10.2217/FON.13.146. 
6. Paolino, D.; Cosco, D.; Gaspari, M.; Celano, M.; Wolfram, J.; Voce, P.; Puxeddu, E.; Filetti, S.; Celia, C.; Ferrari, M.; Russo, D.; Fresta, M. Targeting the Thyroid Gland with Thyroid-Stimulating Hormone (TSH)Nanoliposomes. Biomaterials 2014, 35, 7101-7109, https://doi.org/10.1016/j.biomaterials.2014.04.088.

7. Wagner, V.; Dullaart, A.; Bock, A. K.; Zweck, A. The Emerging Nanomedicine Landscape. In: Nature Biotechnology. Nature Publishing Group October 2006; pp 1211-1217, https://doi.org/10.1038/nbt10061211.

8. Petros, R.A.; Desimone, J.M. Strategies in the Design of Nanoparticles for Therapeutic Applications. In: Nature Reviews Drug Discovery. Nature Publishing Group August 9, 2010; pp 615-627, https://doi.org/10.1038/nrd2591.

9. Zhang, L.; Gu, F.; Chan, J.; Wang, A.; Langer, R.; Farokhzad, O. Nanoparticles in Medicine: Therapeutic Applications and Developments. Clin Pharmacol Ther 2008, 83, 761-769, https://doi.org/10.1038/sj.clpt.6100400.

10. Cattaneo, A.G.; Gornati, R.; Sabbioni, E.; Chiriva-Internati, M.; Cobos, E.; Jenkins, M.R.; Bernardini, G. Nanotechnology and Human Health: Risks and Benefits. J Appl Toxicol 2010, 30, 730-744, https://doi.org/10.1002/jat.1609.

11. Chang, H.I.; Yeh, M.K. Clinical Development of Liposome-Based Drugs: Formulation, Characterization, and Therapeutic Efficacy. Int J Nanomedicine 2012, 7, 49-60, https://doi.org/10.2147/IJN.S26766.

12. Turanek, J.; Koudelka, Š.; Turánek, J. Liposomal Paclitaxel Formulations Noninvasive Sublingual Vaccination and Printed Vaccines View Project Liposomal Paclitaxel Formulations. Artic J Control Release 2012, 163, 322-334, https://doi.org/10.1016/j.jconrel.2012.09.006.

13. Shen, H.; You, J.; Zhang, G.; Ziemys, A.; Li, Q.; Bai, L.; Deng, X.; Erm, D.R.; Liu, X.; Li, C.; Ferrari, M. Cooperative, Nanoparticle-Enabled Thermal Therapy of Breast Cancer. Adv Healthc Mater 2012, 1, 84-89, https://doi.org/10.1002/adhm.201100005.

14. Glazer, E.S.; Zhu, C.; Massey, K.L.; Thompson, C.S.; Kaluarachchi, W.D.; Hamir, A.N.; Curley, S.A. Noninvasive Radiofrequency Field Destruction of Pancreatic Adenocarcinoma Xenografts Treated with Targeted Gold Nanoparticles. Clin Cancer Res 2010, 16, 5712-5721, https://doi.org/10.1158/10780432.CCR-10-2055.

15. Johannsen, M.; Thiesen, B.; Jordan, A.; Taymoorian, K.; Gneveckow, U.; Waldöfner, N.; Scholz, R.; Koch, M.; Lein, M.; Jung, K.; Loening, S.A. Magnetic Fluid Hyperthermia (MFH) Reduces Prostate Cancer Growth in the Orthotopic Dunning R3327 Rat Model. Prostate 2005, 64, 283-292, https://doi.org/10.1002/pros.20213.

16. Ferrari, M. Frontiers in Cancer Nanomedicine: Directing Mass Transport through Biological Barriers. Trends Biotechnol 2010, 28, 181-188, https://doi.org/10.1016/j.tibtech.2009.12.007.

17. Godin, B.; Tasciotti, E.; Liu, X.; Serda, R.E.; Ferrari, M. Multistage Nanovectors: From Concept to Novel Imaging Contrast Agents and Therapeutics. Accounts of Chemical Research 2011, 44, 979-989, https://doi.org/10.1021/ar200077p.

18. Zhu, M.T.; Wang, Y.; Feng, W.Y.; Wang, B.; Wang, M.; Ouyang, H.; Chai, Z.F. Oxidative Stress and Apoptosis Induced by Iron Oxide Nanoparticles in Cultured Human Umbilical Endothelial Cells. Journal of Nanoscience and Nanotechnology 2010, 10, 8584-8590, https://doi.org/10.1166/jnn.2010.2488.

19. Wang, B.; Yin, J.J.; Zhou, X.; Kurash, I.; Chai, Z.; Zhao, Y.; Feng, W. Physicochemical Origin for Free Radical Generation of Iron Oxide Nanoparticles in Biomicroenvironment: Catalytic Activities Mediated by Surface Chemical States. J Phys Chem C 2013, 117, 383-392, https://doi.org/10.1021/jp3101392.

20. Kim, T.H.; Kim, M.; Park, H.S.; Shin, U.S.; Gong, M.S.; Kim, H.W. Size-Dependent Cellular Toxicity of Silver Nanoparticles. J Biomed Mater Res - Part A 2012, 100 A, 1033-1043, https://doi.org/10.1002/jbm.a.34053.

21. Pratsinis, A.; Hervella, P.; Leroux, J.C.; Pratsinis, S.E.; Sotiriou, G.A. Toxicity of Silver Nanoparticles in Macrophages. Small 2013, 9, 2576-2584, https://doi.org/10.1002/smll.201202120.

22. Pan, Y.; Neuss, S.; Leifert, A.; Fischler, M.; Wen, F.; Simon, U.; Schmid, G.; Brandau, W.; Jahnen-Dechent, W. Size-Dependent Cytotoxicity of Gold Nanoparticles. Small 2007, 3, 1941-1949, https://doi.org/10.1002/smll.200700378.

23. Pankaj, K.T.; Shruti, V.S.; Anami, A. Synthesis of Metal Nanoparticals: A Biological Prospective for Analysis. Int J Rev Artic Pharm Innov 2012, 2, 48-60.

24. Johnston, H.J.; Hutchison, G.R.; Christensen, F.M.; Peters, S.; Hankin, S.; Aschberger, K.; Stone, V. A Critical Review of the Biological Mechanisms Underlying the in Vivo and in Vitro Toxicity of Carbon Nanotubes: The Contribution of Physico-Chemical Characteristics. Nanotoxicology 2010, 4, 207-246, https://doi.org/10.3109/17435390903569639.

25. Yan, L.; Zhao, F.; Li, S.; Hu, Z.; Zhao, Y. Low-Toxic and Safe Nanomaterials by Surface-Chemical Design, Carbon Nanotubes, Fullerenes, Metallofullerenes, and Graphenes. Nanoscale 2011, 3, 362-382, https://doi.org/10.1039/c0nr00647e.

26. Chen, C.; Xing, G.; Wang, J.; Zhao, Y.; Li, B.; Tang, J.; Jia, G.; Wang, T.; Sun, J.; Xing, L.; Yuan, H.; Gao, Y.; Meng, H.; Chen, Z.; Zhao, F.; Chai, Z.; Fang, X. Multihydroxylated [Gd@C82(OH)22]n Nanoparticles: Antineoplastic Activity of High Efficiency and Low Toxicity. Nano Lett 2005, 5, 2050-2057, https://doi.org/10.1021/n1051624b. 
27. Zhao, F.; Zhao, Y.; Liu, Y.; Chang, X.; Chen, C.; Zhao, Y. Cellular Uptake, Intracellular Trafficking, and Cytotoxicity of Nanomaterials. Small 2011, 7, 1322-1337, https://doi.org/10.1002/smll.201100001.

28. Gupta, A. K.; Wells, S. Surface-Modified Superparamagnetic Nanoparticles for Drug Delivery: Preparation, Characterization, and Cytotoxicity Studies. IEEE Trans Nanobioscience 2004, 3, 66-73.

29. Barenholz, Y. Doxil® - The First FDA-Approved Nano-Drug: Lessons Learned. Journal of Controlled Release 2012, 160, 117-134, https://doi.org/10.1016/j.jconrel.2012.03.020.

30. Li, K.C.P.; Pandit, S.D.; Guccione, S.; Bednarski, M.D. Molecular Imaging Applications in Nanomedicine. Biomedical Microdevices 2004, 6, 113-116, https://doi.org/10.1023/B:BMMD.0000031747.05317.81.

31. Bae, Y.H.; Park, K. Targeted drug delivery to tumors: Myths, reality and possibility. Journal of Controlled Release 2011, 153, 198-205, https://doi.org/10.1016/j.jconrel.2011.06.001.

32. Matsumura, Y.; Maeda, H. A New Concept for Macromolecular Therapeutics in Cancer Chemotherapy: Mechanism of Tumoritropic Accumulation of Proteins and the Antitumor Agent Smancs. Cancer Res 1986, 46.

33. Maeda, H.; Wu, J.; Sawa, T.; Matsumura, Y.; Hori, K. Tumor Vascular Permeability and the EPR Effect in Macromolecular Therapeutics: A Review. J Control Release 2000, 65, 271-284, https://doi.org/10.1016/S0168-3659(99)00248-5.

34. Wolfram, J.; Suri, K.; Huang, Y.; Molinaro, R.; Borsoi, C.; Scott, B.; Boom, K.; Paolino, D.; Fresta, M.; Wang, J.; Ferrari, M.; Celoa, C.; Shen, H. Evaluation of Anticancer Activity of Celastrol Liposomes in Prostate Cancer Cells. J Microencapsul 2014, 31, 501-50,. https://doi.org/10.3109/02652048.2013.879932.

35. Celia, C.; Trapasso, E.; Locatelli, M.; Navarra, M.; Ventura, C.A.; Wolfram, J.; Carafa, M.; Morittu, V. M.; Britti, D.; Di Marzio, L.; Paolino, D. Anticancer Activity of Liposomal Bergamot Essential Oil (BEO) on Human Neuroblastoma Cells. Colloids Surfaces B Biointerfaces 2013, 112, 548-553, https://doi.org/10.1016/j.colsurfb.2013.09.017.

36. Norvaisas, P.; Ziemys, A. The Role of Payload Hydrophobicity in Nanotherapeutic Pharmacokinetics. $J$ Pharm Sci 2014, 103, 2147-2156, https://doi.org/10.1002/jps.23996.

37. Yang, Y.; Wolfram, J.; Boom, K.; Fang, X.; Shen, H.; Ferrari, M. Hesperetin Impairs Glucose Uptake and Inhibits Proliferation of Breast Cancer Cells. Cell Biochem Funct 2013, 31, 374-379, https://doi.org/10.1002/cbf.2905.

38. Ruiz-Delgado, G.J.; Mancías-Guerra, C.; Tamez-Gómez, E.L.; Rodríguez-Romo, L.N.; López-Otero, A.; Hernández-Arizpe, A.; Gómez-Almaguer, D.; Ruiz-Argüelles, G.J. Dimethyl Sulfoxide-Induced Toxicity in Cord Blood Stem Cell Transplantation: Report of Three Cases and Review of the Literature. Acta Haematologica 2009, 122, 1-5, https://doi.org/10.1159/000227267.

39. Zenhäusern, R.; Tobler, A.; Leoncini, L.; Hess, O.M.; Ferrari, P. Fatal Cardiac Arrhythmia after Infusion of Dimethyl Sulfoxide-Cryopreserved Hematopoietic Stem Cells in a Patient with Severe Primary Cardiac Amyloidosis and End-Stage Renal Failure. Ann Hematol 2000, 79, 523-526, https://doi.org/10.1007/s002770000186.

40. Montaguti, P.; Melloni, E.; Cavalletti, E. Acute intravenous toxicity of dimethyl sulfoxide, polyethylene glycol 400, dimethylformamide, absolute ethanol, and benzyl alcohol in inbred mouse strains. ArzneimittelForschung 1994, 44, 566-570.

41. Tyagi, P.K.; Mishra, M.; Khan, N.; Tyagi, S.; Sirohi, S. Toxicological Study of Silver Nanoparticles on Gut Microbial Community Probiotic. Environ Nanotechnology, Monit Manag 2016, 5, 36-43, https://doi.org/10.1016/j.enmm.2016.01.003.

42. Gelderblom, H.; Verweij, J.; Nooter, K.; Sparreboom, A. Cremophor EL: the drawbacks and advantages of vehicle selection for drug formulation. European Journal of Cancer 2001, 37, 1590-1598, https://doi.org/10.1016/S0959-8049(01)00171-X.

43. Cho, H.J.; Park, J.W.; Yoon, I.S.; Kim, D.D. Surface-Modified Solid Lipid Nanoparticles for Oral Delivery of Docetaxel: Enhanced Intestinal Absorption and Lymphatic Uptake. Int J Nanomedicine 2014, 9, 495-504, https://doi.org/10.2147/IJN.S56648.

44. Spataro, G.; Malecaze, F.; Turrin, C.O.; Soler, V.; Duhayon, C.; Elena, P.P.; Majoral, J.P.; Caminade, A. M. Designing Dendrimers for Ocular Drug Delivery. Eur J Med Chem 2010, 45, 326-334, https://doi.org/10.1016/j.ejmech.2009.10.017.

45. Maeda, H.; Sawa, T.; Konno, T. Mechanism of Tumor-Targeted Delivery of Macromolecular Drugs, Including the EPR Effect in Solid Tumor and Clinical Overview of the Prototype Polymeric Drug SMANCS. J Control Release 2001, 74, 47-61, https://doi.org/10.1016/S0168-3659(01)00309-1.

46. Ziemba, B.; Matuszko, G.; Bryszewska, M.; Klajnert, B. Cellular \& Molecular Biology Letters Mini Review Influence Of Dendrimers On Red Blood Cells. cmbl.biomedcentral.com 2011, 17, 21-35.

47. Shegokar, R.; Müller, R.H. Nanocrystals: Industrially Feasible Multifunctional Formulation Technology for Poorly Soluble Actives. Int J Pharm 2010, 399, 129-139, https://doi.org/10.1016/j.ijpharm.2010.07.044.

48. Tyagi, P.K. Production of Metal Nanoparticles from Biological Resources. Artic Int J Curr Microbiol Appl Sci 2016, 5, 548-558, https://doi.org/10.20546/ijcmas.2016.503.064.

49. Gao, L.; Liu, G.; Ma, J.; Wang, X.; Zhou, L.; Li, X. Drug Nanocrystals: In Vivo Performances. Journal of Controlled Release 2012, 160, 418-430, https://doi.org/10.1016/j.jconrel.2012.03.013. 
50. Devalapally, H.; Chakilam, A.; Amiji, M.M. Role of Nanotechnology in Pharmaceutical Product Development. J Pharm Sci 2007, 96, 2547-2565, https://doi.org/10.1002/jps.20875.

51. Martins, S.; Sarmento, B.; Ferreira, D.C.; Souto, E.B. Lipid-Based Colloidal Carriers for Peptide and Protein Delivery - Liposomes versus Lipid Nanoparticles. Int J Nanomedicine 2007, 2, 595-607.

52. Italia, J.L.; Yahya, M.M.; Singh, D.; Ravi Kumar, M.N.V. Biodegradable Nanoparticles Improve Oral Bioavailability of Amphotericin B and Show Reduced Nephrotoxicity Compared to Intravenous Fungizone®. Pharm Res 2009, 26, 1324-1331, https://doi.org/10.1007/s11095-009-9841-2.

53. Onoue, S.; Uchida, A.; Kuriyama, K.; Nakamura, T.; Seto, Y.; Kato, M.; Hatanaka, J.; Tanaka, T.; Miyoshi, H.; Yamada, S. Novel Solid Self-Emulsifying Drug Delivery System of Coenzyme Q 10 with Improved Photochemical and Pharmacokinetic Behaviors. Eur J Pharm Sci 2012, 46, 492-499, https://doi.org/10.1016/j.ejps.2012.03.015.

54. Strickley, R.G. Solubilizing Excipients in Oral and Injectable Formulations Article in Pharmaceutical Research. Springer 2004, 21, 201-230, https://doi.org/10.1023/B:PHAM.0000016235.32639.23.

55. Kawabata, Y.; Wada, K.; Nakatani, M.; Yamada, S.; Onoue, S. Formulation Design for Poorly WaterSoluble Drugs Based on Biopharmaceutics Classification System: Basic Approaches and Practical Applications. Int J Pharm 2011, 420, 1-10, https://doi.org/10.1016/j.ijpharm.2011.08.032.

56. Onoue, S.; Sato, H.; Ogawa, K.; Kojo, Y.; Aoki, Y.; Kawabata, Y.; Wada, K.; Mizumoto, T.; Yamada, S. Inhalable Dry-Emulsion Formulation of Cyclosporine A with Improved Anti-Inflammatory Effects in Experimental Asthma/COPD-Model Rats. Eur J Pharm Biopharm 2012, 80, 54-60, https://doi.org/10.1016/j.ejpb.2011.10.003.

57. Teshima, M.; Fumoto, S.; Nishida, K.; Nakamura, J.; Ohyama, K.; Nakamura, T.; Ichikawa, N.; Nakashima, M.; Sasaki, H. Prolonged Blood Concentration of Prednisolone after Intravenous Injection of Liposomal Palmitoyl Prednisolone. J Control Release 2006, 112, 320-328, https://doi.org/10.1016/j.jconrel.2006.03.004.

58. Clift, M.J.D.; Raemy, D.O.; Endes, C.; Ali, Z.; Lehmann, A.D.; Brandenberger, C.; Petri-Fink, A.; Wick, P.; Parak, W.J.; Gehr, P.; Schins, R.P.F.; Rothen-Rutishauser, B. Can the Ames Test Provide an Insight into Nano-Object Mutagenicity? Investigating the Interaction between Nano-Objects and Bacteria. Nanotoxicology 2013, 7, 1373-1385, https://doi.org/10.3109/17435390.2012.741725.

59. Ng, C.T.; Li, J.J.; Bay, B.H.; Yung, L.Y.L. Current Studies into the Genotoxic Effects of Nanomaterials. $J$ Nucleic Acids 2010, 2010, https://doi.org/10.4061/2010/947859.

60. Wörle-Knirsch, J.M.; Pulskamp, K.; Krug, H.F. Oops They Did It Again! Carbon Nanotubes Hoax Scientists in Viability Assays. Nano Lett 2006, 6, 1261-1268, https://doi.org/10.1021/n1060177c.

61. Oberdörster, G. Safety Assessment for Nanotechnology and Nanomedicine: Concepts of Nanotoxicology. In Journal of Internal Medicine 2010, 267, 89-105, https://doi.org/10.1111/j.1365-2796.2009.02187.x.

62. Long, T.C.; Tajuba, J.; Sama, P.; Saleh, N.; Swartz, C.; Parker, J.; Hester, S.; Lowry, G.V.; Veronesi, B. Nanosize Titanium Dioxide Stimulates Reactive Oxygen Species in Brain Microglia and Damages Neurons in Vitro. Environ Health Perspect 2007, 115, 1631-1637, https://doi.org/10.1289/ehp.10216.

63. Oberdörster, G.; Yu, C.P. The Carcinogenic Potential of Inhaled Diesel Exhaust: A Particle Effect? J Aerosol Sci 1990, 21, https://doi.org/10.1016/0021-8502(90)90265-Y.

64. Tyagi, P.K.; Sarsar, V.; Ahuja, A. Synthesis of Metal Nanoparticals: A Biological Prospective for Analysis Characterisation of Lindane Degrading Bacteria from the Environment View Project Synthesis of Metal Nanoparticals: A Biological Prospective for Analysis. Interantional Journal of Pharmaceutical Innovations 2012, 2 .

65. Corathers, S.D.; Falciglia, M. The Role of Hyperglycemia in Acute Illness: Supporting Evidence and Its Limitations. Nutrition 2011, 27, 276-281, https://doi.org/10.1016/j.nut.2010.07.013.

66. Lam, C.W.; James, J.T.; McCluskey, R.; Hunter, R.L. Pulmonary Toxicity of Single-Wall Carbon Nanotubes in Mice 7 and 90 Days after Intractracheal Instillation. Toxicol Sci 2004, 77, 126-134, https://doi.org/10.1093/toxsci/kfg243.

67. Ge, C.; Li, Y.; Yin, J.J.; Liu, Y.; Wang, L.; Zhao, Y.; Chen, C. The Contributions of Metal Impurities and Tube Structure to the Toxicity of Carbon Nanotube Materials. NPG Asia Mater 2012, 4, https://doi.org/10.1038/am.2012.60.

68. Naahidi, S.; Jafari, M.; Edalat, F.; Raymond, K.; Khademhosseini, A.; Chen, P. Biocompatibility of Engineered Nanoparticles for Drug Delivery. J Control Release 2013, 166, 182-194, https://doi.org/10.1016/j.jconrel.2012.12.013.

69. Yang, W.; Peters, J.I.; Williams, R.O. Inhaled Nanoparticles-A Current Review. International Journal of Pharmaceutics 2008, 356, 239-247, https://doi.org/10.1016/j.ijpharm.2008.02.011.

70. Tyagi, S.; Tyagi, P.K.; Gola, D.; Chauhan, N.; Bharti, R.K. Extracellular Synthesis of Silver Nanoparticles Using Entomopathogenic Fungus: Characterization and Antibacterial Potential. SN Appl Sci 2019, 1, https://doi.org/10.1007/s42452-019-1593-y.

71. Subhanandaraj, T.; Raghavan, K.; Narayanan, R,NanoBioScience, R. Antibacterial and Antibiofilm Activity of Probiotic Based Silver Nanoparticles Is a Green Approach in Biomedical Applications. Lett Appl NanoBioScience 2020, 9, 988-994, https://doi.org/10.33263/lianbs92.988994. 
72. Nel, A.; Xia, T.; Mädler, L.; Li, N. Toxic Potential of Materials at the Nanolevel. Science 2006, 311 , https://doi.org/10.1126/science.1114397.

73. Zhu, S.; Gong, L.; Li, Y.; Xu, H.; Gu, Z.; Zhao, Y. Safety Assessment of Nanomaterials to Eyes: An Important but Neglected Issue. Advanced Science. John Wiley and Sons Inc. 2019. https://doi.org/10.1002/advs.201802289.

74. Shahbazi, M.-A.; Santos, H.A. Improving Oral Absorption Via Drug-Loaded Nanocarriers: Absorption Mechanisms, Intestinal Models and Rational Fabrication Tumor-Targeted Nucleic Acid Delivery View Project Send Orders of Reprints at Bspsaif@emirates.Net.Ae Improving Oral Absorption Via Drug-Loaded Nanocarriers: Absorption Mecha-Nisms, Intestinal Models and Rational Fabrication. Curr Drug Metab 2013, 14, 28-56, https://doi.org/10.2174/138920013804545133.

75. Reddy, L.H.; Sharma, R.K.; Chuttani, K.; Mishra, A.K.; Murthy, R.R. Etoposide-Incorporated Tripalmitin Nanoparticles with Different Surface Charge: Formulation, Characterization, Radiolabeling, and Biodistribution Studies. AAPS Journal 2004, 6, https://doi.org/10.1208/aapsj060323.

76. Manjunath, K.; Venkateswarlu, V. Pharmacokinetics, tissue distribution and bioavailability of clozapine solid lipid nanoparticles after intravenous and intraduodenal administration. Journal of Controlled Release 2005, 107, 215-228, https://doi.org/10.1016/j.jconrel.2005.06.006.

77. Piao, H.; Kamiya, N.; Hirata, A.; Fujii, T.; Goto, M. A Novel Solid-in-Oil Nanosuspension for Transdermal Delivery of Diclofenac Sodium. Pharm Res 2008, 25, 896-901,https://doi.org/10.1007/s11095-007-9445-7.

78. Watanabe, M.; Kawano, K.; Yokoyama, M.; Opanasopit, P.; Okano, T.; Maitani, Y. Preparation of Camptothecin-Loaded Polymeric Micelles and Evaluation of Their Incorporation and Circulation Stability. Int J Pharm 2006, 308, 183-189, https://doi.org/10.1016/j.ijpharm.2005.10.030.

79. Matsumura, Y.; Hamaguchi, T.; Ura, T.; Muro, K.; Yamada, Y.; Shimada, Y.; Shirao, K.; Okusaka, T.; Ueno, H.; Ikeda, M.; Watanabe, N. Phase I clinical trial and pharmacokinetic evaluation of NK911, a micelleencapsulated doxorubicin. British Journal of Cancer 2004, 91, 1775-1781, https://doi.org/10.1038/sj.bjc.6602204.

80. Kabanov, A.V.; Alakhov, V.Y. Pluronic® Block Copolymers in Drug Delivery: From Micellar Nanocontainers to Biological Response Modifiers. Crit Rev Ther Drug Carrier Syst 2002, 19, 1-72, https://doi.org/10.1615/CritRevTherDrugCarrierSyst.v19.i1.10.

81. Kato, K.; Chin, K.; Yoshikawa, T.; Yamaguchi, K.; Tsuji, Y.; Esaki, T.; Sakai, K.; Kimura, M.; Hamaguchi, T.; Shimada, Y.; Matsumura, Y.; Ikeda, R. Phase II study of NK105, a paclitaxel-incorporating micellar nanoparticle, for previously treated advanced or recurrent gastric cancer. Investigational New Drugs 2012, 30, 1621-1627, https://doi.org/10.1007/s10637-011-9709-2.

82. Fanciullino, R.; Ciccolini, J.; Milano, G. Challenges, Expectations and Limits for Nanoparticles-Based Therapeutics in Cancer: A Focus on Nano-Albumin-Bound Drugs. Crit Rev Oncol Hematol 2013, 88, 504-513, https://doi.org/10.1016/j.critrevonc.2013.06.010.

83. Mora-Huertas, C. E.; Fessi, H.; Elaissari, A. Polymer-Based Nanocapsules for Drug Delivery. International Journal of Pharmaceutics 2010, 385, 113-142, https://doi.org/10.1016/j.ijpharm.2009.10.018.

84. Hrkach, J.; Von Hoff, D.; Ali, M.M.; Andrianova, E.; Auer, J.; Campbell, T.; De Witt, D.; Figa, M.; Figueiredo, M.; Horhota, A.; Low, S.; McDonnell, K.; Peeke, E.; Retnarajan, B.; Sabnis, A.; Schnipper, E.; Song, J.J.; Song, Y.H.; Summa, J.; Tompsett, D.; Troiano, G.; Van Geen Hoven, T.; Wright, J.; LoRusso, P.; Kantoff, P.W.; Bander, N.H.; Sweeney, C.; Farokhzad, O.C.; Langer, R.; Zale, S. Preclinical Development and Clinical Translation of a PSMA-Targeted Docetaxel Nanoparticle with a Differentiated Pharmacological Profile. J Science Translational Medicine 2012, 4, https://doi.org/10.1126/scitranslmed.3003651.

85. Ramos, A.P.; Cruz, M.A.E.; Tovani, C.B.; Ciancaglini, P. Biomedical Applications of Nanotechnology. Biophysical Reviews 2017, 9, 79-89, https://doi.org/10.1007/s12551-016-0246-2.

86. Tyagi, P.K. Use of Biofabricated Silver Nanoparticles-Conjugated with Antibiotic against Multidrug Resistant Pathogenic Bacteria. Biol Insights 2016, 1, 1-2.

87. Biazar, E.; Majdi; Zafari, M.; Avar, M.; Aminifard, S.; Zaeifi, D.; Jafarpour, A.; Montazeri, G. Nanotoxicology and Nanoparticle Safety in Biomedical Designs. Int J Nanomedicine, 2011, 6, https://doi.org/10.2147/ijn.s16603.

88. Vega-Villa, K.R.; Takemoto, J.K.; Yáñez, J.A.; Remsberg, C.M.; Forrest, M.L.; Davies, N.M. Clinical Toxicities of Nanocarrier Systems. Adv Drug Deliv Rev 2008, 60, 929-938, https://doi.org/10.1016/j.addr.2007.11.007.

89. Drobne, D. Nanotoxicology for Safe and Sustainable Nanotechnology. Arhiv za Higijenu Rada $i$ Toksikologiju 2007, 58, 471-478, https://doi.org/10.2478/v10004-007-0040-4.

90. Wick, P.; Manser, P.; Limbach, L.K.; Dettlaff-Weglikowska, U.; Krumeich, F.; Roth, S.; Stark, W.J.; Bruinink, A. The Degree and Kind of Agglomeration Affect Carbon Nanotube Cytotoxicity. Toxicol Lett 2007, 168, 121-131, https://doi.org/10.1016/j.toxlet.2006.08.019.

91. Choi, H.S.; Frangioni, J.V. Nanoparticles for Biomedical Imaging: Fundamentals of Clinical Translation. journals.sagepub.com 2010, 9, 291-310, https://doi.org/10.2310/7290.2010.00031. 
92. Ferdous, Z.; Nemmar, A. Health Impact of Silver Nanoparticles: A Review of the Biodistribution and Toxicity Following Various Routes of Exposure. Int J Mol Sci 2020, 21, https://doi.org/10.3390/ijms21072375.

93. Savage, D. T.; Hilt, J. Z.; Dziubla, T. D. In Vitro Methods for Assessing Nanoparticle Toxicity. In Methods in Molecular Biology; Humana Press Inc., 2019; Vol. 1894, pp 1-29, https://doi.org/10.1007/978-1-49398916-4_1.

94. Stern, S.T.; McNeil, S.E. Nanotechnology Safety Concerns Revisited. Toxicol Sci 2008, 101, 4-21, https://doi.org/10.1093/toxsci/kfm169.

95. Liu, H.; Wang, X.; Wu, Y.; Hou, J.; Zhang, S.; Zhou, N.; Wang, X. Toxicity Responses of Different Organs of Zebrafish (Danio Rerio) to Silver Nanoparticles with Different Particle Sizes and Surface Coatings. Environ Pollut, 2019, 246, 414-422, https://doi.org/10.1016/j.envpol.2018.12.034. 